\title{
AN ACOUSTIC EMISSION STUDY OF MIXED MODE CRACK PROPAGATION IN REINFORCED CONCRETE BEAMS
}

\author{
PRASHANTH M. H * and J. M. CHANDRA KISHEN ${ }^{\ddagger}$ \\ * Graduate Student, ${ }^{\ddagger}$ Professor \\ Indian Institute of Science, Bangalore, India \\ e-mail: mh_prashanth@rediff.com, chandrak@civil.iisc.ernet.in
}

Key words: Mixed mode, Reinforced concrete, Acoustic Emission

\begin{abstract}
This paper presents an experimental study on mixed crack propagation in reinforced concrete beam. The specimen was reinforced with single longitudinal bar of diameter $8 \mathrm{~mm}$ (percentage $=0.66 \%$ ) with no stirrups. The notch is provided at the quarter span, as it is the region prone for mixed mode crack initiation and propagation. The specimen is tested in three point bending under displacement/stroke control in the closed loop servo controlled hydraulic testing machine. The results of load, displacement, CMOD and strain in the steel are acquired in the data acquisition system. The results were analysed and related failure mechanisms observed in reinforced concrete are cracking, yielding of steel, shear, slippage and de-bonding between steel and concrete. The acoustic emission technique is used for monitoring the crack growth in reinforced concrete beam using six AE-sensors mounted on the specimen. The acoustic emission events location is used to understand the cracking and fracture process in zone of tensile and shear cracking. The AE data of events, amplitude, absolute energy and time are analysed to understand cracking, energy released and fracture processes in opening and mixed modes and to compare them.
\end{abstract}

\section{INTRODUCTION}

The mixed mode fracture has been of greater importance for the wide range of civil engineering structures. Current design codes for the shear resistance of reinforced concrete are still based on the empirical results. Under shear forces, crack tends to propagate in opening and sliding mode. For the mixed mode fracture in the reinforced concrete, the determination of crack trajectory for the crack instability is more difficult than the opening mode. Hence, an attempt has been made to use the acoustic emission technique to understand the mixed mode crack propagation in reinforced concrete. Few researchers have studied the mixed mode crack propagation in reinforced concrete. Carmona et al. [1] have performed experimental studies on investigating mixed mode fracture of reinforced concrete with various ratios of longitudinal and inclined reinforcement. These experiments has helped them in understanding the mechanisms of crack initiation and propagation through reinforcing bars under mixed mode condition. Carpinteri et al. [2] have presented experimental research program on validating the mechanical model connecting failure modes with the cracking processes in reinforced concrete beams.

The Acoustic Emission (AE) technique is a widely used tool for non destructive evaluation of materials. $\mathrm{AE}$ is a class of phenomenon where the transient elastic waves are generated by the rapid release of energy from the localized sources within the material when the structure is subjected to external stimuli. The localized changes in the material are initiation and growth of micro cracks, friction, slip, distortion and 
dislocation. The acoustic emission technique offers the possibility of capturing the damage process, including the location and time of occurrence. AE technique can be used for online monitoring of materials or during service of structures.

There is very little information available in the literature regarding the use of acoustic emission technique for studying mixed mode crack growth in reinforced concrete. Few attempts have been made by researchers to study acoustic emission in the tensile and shear mode failures. Momoki et al. [3] have used acoustic emission to characterize the behaviour of composite concrete elements under flexure. Further, they found that AE parameters were useful in distinguishing the flexure and shear fracture modes. Aggelis et al. [4] have used acoustic emission to monitor the steel fiber reinforced concrete beams under bending. They observed that fiber content resulted in a shift from the tensile to the shear mode of failure due to improvements of the weak tensile properties of concrete. Kaphle [5] has studied the use of acoustic emission data tools in structural health monitoring applications. They explored the various tools for analysis of recorded AE data to address discriminating signals from different sources and quantifying damage levels for severity assessment. Apart from few attempts, very little has been reported in the literature on the use of $\mathrm{AE}$ technique for monitoring the mixed mode crack growth in reinforced concrete.

The main objective of the present work is to study the mixed mode crack propagation in reinforced concrete beams using acoustic emission technique. The acoustic emission events location is used to understand the cracking and fracture process in the zones of tensile and shear cracking. The AE data of events, amplitude, absolute energy and time are analysed to understand cracking, energy released and fracture processes in opening mode and mixed mode.

\section{EXPERIMENTAL PROGRAM}

\subsection{Materials and Mix Proportions}

Ordinary Portland cement OPC 53 grade is used in casting of concrete specimens. Locally available natural sand and crushed granite (of $12.5 \mathrm{~mm}$ ) are used as fine and coarse aggregates, respectively. The concrete mix design is done using the ACI method and the mix proportion of cement, fine aggregate and coarse aggregate obtained is $1: 1.86: 2.61$ by weight. A water to cement ratio of 0.54 is used throughout the entire mix. The average compressive strength of companion cubes of dimension $150 \mathrm{~mm}$ was $51 \mathrm{MPa}$. All the specimens were cured in water for 28 days. The reinforcement used is high yield strength deformed steel bar of $8 \mathrm{~mm}$ diameter of grade Fe500 with the tested yield stress of $550 \mathrm{~N} / \mathrm{mm}^{2}$.

The specimens were of length to depth ratio $(L / D)$ of 4.5 , span to depth ratio $(S / D)$ of 4 , and notch to depth ratio $\left(a_{0} / D\right)$ of 0.2 , which is provided at the quarter span $(D)$. The specimen was reinforced with single longitudinal bar with diameter of $8 \mathrm{~mm}\left(\left(A_{s t} * 100\right) / B D\right.$ $=0.66 \%)$ with no stirrups. The reinforcement is provided above the initial notch tip. A gap of 12 to $14 \mathrm{~mm}$ is provided between the outer steel bar and the notch tip. The details of dimensions of beam specimen is shown in Table 1 . The geometric details of specimen is as shown in Figure 1 .

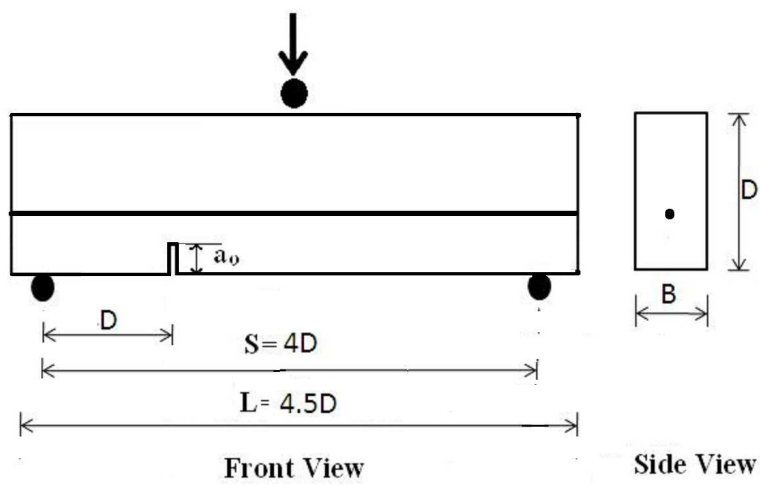

Figure 1: Details of geometry of the specimens 
Table 1: Details of dimensions of beam

\begin{tabular}{cccc}
\hline $\begin{array}{c}\text { Depth } \\
\mathrm{D}(\mathrm{mm})\end{array}$ & $\begin{array}{c}\text { Span } \\
\mathrm{S}(\mathrm{mm})\end{array}$ & $\begin{array}{c}\text { Length } \\
\mathrm{L}(\mathrm{mm})\end{array}$ & $\begin{array}{c}\text { Notch Size } \\
a_{0}(\mathrm{~mm})\end{array}$ \\
\hline 150 & 600 & 675 & 30 \\
\hline
\end{tabular}

\subsection{Testing of Specimens}

The specimen is tested in the closed loop servo controlled hydraulic testing machine. The test is performed in displacement/stroke control at the rate of $0.001 \mathrm{~mm} / \mathrm{sec}$. The testing of the beam specimen and instrumentation is as shown in Figure 2. An in-built load cell of 50 $\mathrm{kN}$ was used for measuring the load. The load point displacement is measured at the midspan using linear variable displacement transformer (LVDT). The crack mouth opening displacement (CMOD) measurements were taken at the notch provided at quarter span using the clip gauge. A electrical resistance strain gauge of $120 \mathrm{ohms}$ is used at the midspan of reinforcing bar to measure the axial strain.

The details of AE sensor location used for acquisition of AE data is shown in Figure 3. In order to obtain a 3D location of AE-events, six AE-sensors are mounted on the specimen in a triangulation scheme with three sensors in the front face and three sensors behind as shown in Figure 3 to capture the cracking and fracture processes in opening and mixed modes. The AE data such as hits, events, absolute energy, signal strength, spatial positions, amplitude and time are simultaneously acquired using data acquisition system during the experiments. The resonant type differential sensors R6D, having a diameter and height of $19 \mathrm{~mm}$ and 22 $\mathrm{mm}$, respectively with an operating frequency of 35 to $100 \mathrm{kHz}$ are used in the experimental work. High vacuum silicon grease has been used as couplant. The AE signals are amplified with a gain of $40 \mathrm{~dB}$ in a (PAC) pre-amplifier. An eight-channel AE-WIN for SAMOS E2.0 (Sensor based Acoustic Multichannel Operating System), developed by Physical Acoustics Corporation (PAC)-USA has been used for AE data acquisition. A threshold of $40 \mathrm{~dB}$, which is normally used for concrete is adopted.

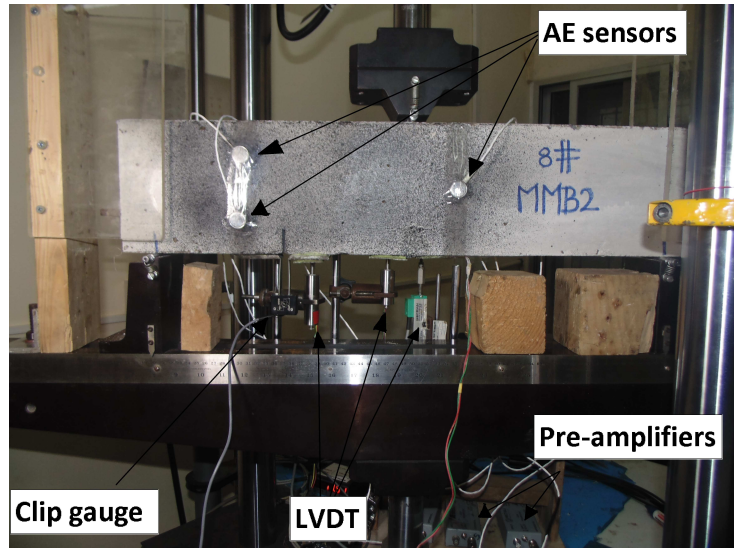

Figure 2: Testing of beam specimen and instrumentation such as clip gauge, LVDT, AE sensors and preamplifiers

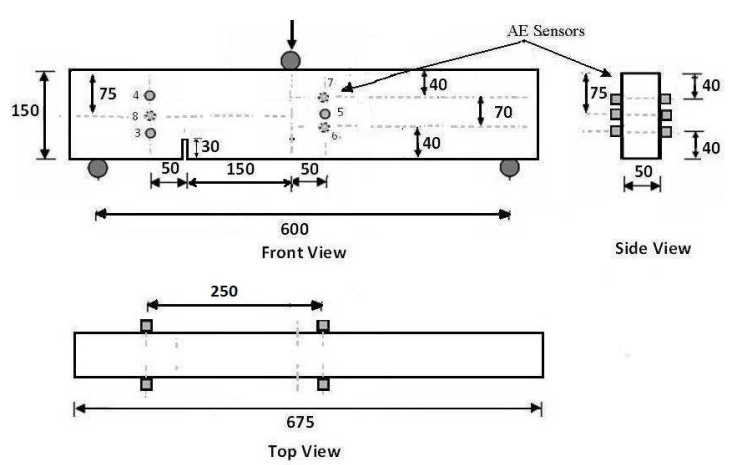

Figure 3: AE sensor location for the specimen

\section{RESULTS AND DISCUSSION}

\subsection{Results from Mechanical Testing}

The experimental data such as load, CMOD, displacement and strain, acquired during the tests are analysed. The plots in Figures 4 to 6 are useful to understand the behavior of mixed mode crack propagation in the tested reinforced concrete beams. The plot of load vs displacement in Figure 4 shows various points A,B,C,D,E,F,G,H,I to understand the behaviour. Load displacement relation is linear until the point $\mathrm{A}$ and entire load is taken by concrete. At point $\mathrm{A}$, the micro cracks have started to form at the bottom of the midspan and these cracks have reached the reinforcement around the point $\mathrm{B}$. From point B onwards, the strain in steel increases as seen in the plot of Figure 6 and load 
has started to transfer from concrete to steel and the cracking has started to propagate beyond the level of reinforcement till the point $\mathrm{C}$. Around the point $\mathrm{C}$, a band of intensive microcracking and damage takes place at the midspan section and the mixed mode micro-cracking has started to initiate at the notch placed at the quarter span. This crack propagates in the direction to the point of loading, till the mark $\mathrm{D}$ in the plot. From the similar point in plot of Figure 5, the non-linear increase in the CMOD readings near the quarter span is observed. At point $\mathrm{D}$, the crack length and width in diagonal direction increases causing the shear failure in concrete as seen in the picture of Figure 15 thereby dropping the load to point $\mathrm{F}$ in the plot. Further the load is carried by the reinforcement with increase displacement till the point $\mathrm{G}$ in the plot. The de-bonding of concrete and reinforcement has taken place as shown in picture of Figure 16 further dropping the load to point $\mathrm{H}$ in the plot and resulting in failure.

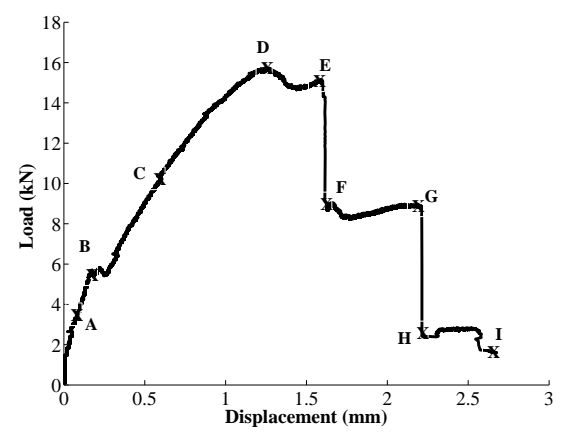

Figure 4: Load vs Displacement

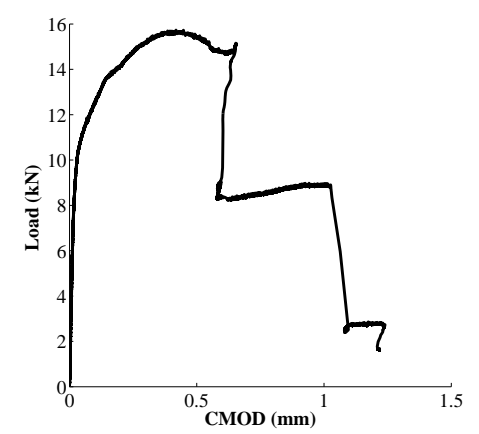

Figure 5: Load vs CMOD

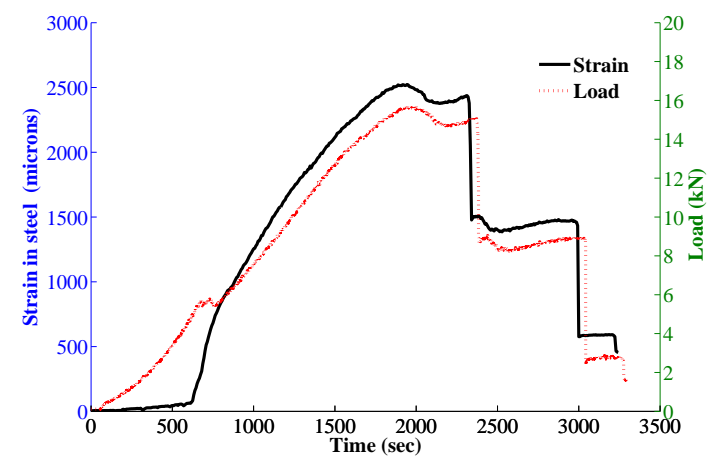

Figure 6: Load vs strain in reinforcement of specimen

\subsection{Results on Acoustic Emission (AE)}

\subsubsection{AE Events}

$\mathrm{AE}$ events are a result of micro cracking in the concrete material and spread of these events indicate micro crack distribution and damage taking place. Picture in Figure 7 shows the front view and top view of AE events at different points of loading with corresponding numbers shown in plot of Figure 8 . The fracture processes of specimen in the testing is discussed below. It is seen prior to point 1 , the micro cracks have initiated and propagated in the opening mode in the midpan of the beam. From point 1 to 2, the AE events appeared with the band of events indicating that damage has started to localize and a continuous major crack crossing beyond the level of reinforcement. After point 2 the microcracks have started to initiate at notch position at the quarter span and propagating to the loaded point which is in diagonal direction, indicating that mixed mode crack propogation taking place. From point 2 to 4 , the density of mixed mode crack events has increased in the region from notch position at the quarter span indicating the load transfer mechanism taking place. From point 4 to 5 , the mixed mode crack length and width increases, causing shear failure in concrete leading to further rise of $\mathrm{AE}$ events. From point 5 to 6 , the slippage is occurring in reinforcement causing the de-bonding of concrete and steel to take place, causing additional rise of $\mathrm{AE}$ events. 


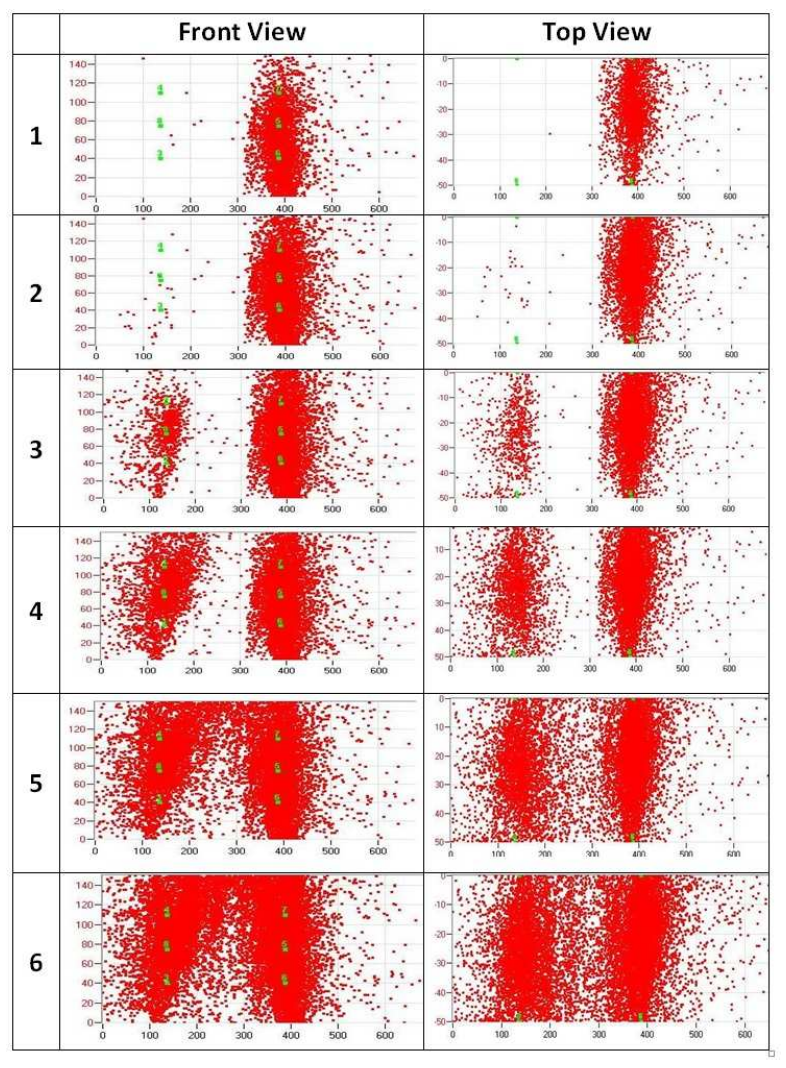

Figure 7: Location for AE events for specimen corresponding to points in the plot of cumulative events and load vs time

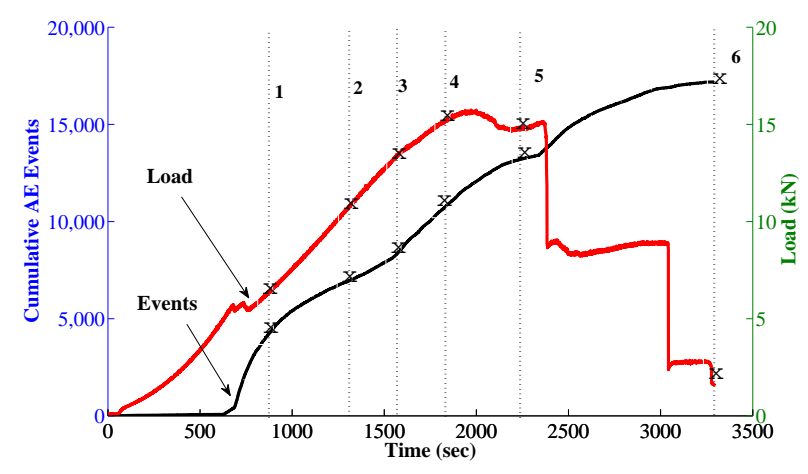

Figure 8: Plot of cumulative events and load vs time

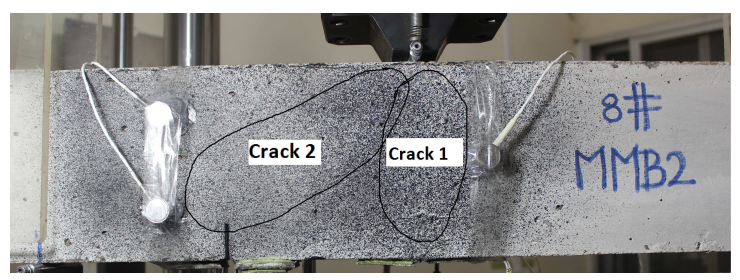

Figure 9: Figure showing the zone of crack 1 and crack 2

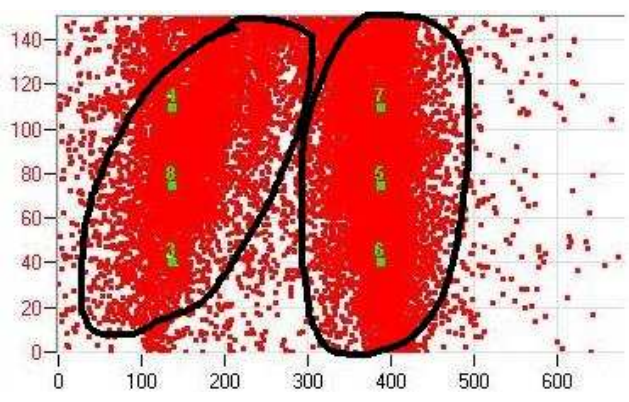

Figure 10: Location for AE events for specimen corresponding to opening mode and mixed mode

Figures 9 and 10 shows the picture, wherein the events of zones are divided as crack 1 (opening mode) and crack 2 (mixed mode). Figure 11 shows the cumulative AE events and load versus time for crack 1 (opening mode), crack 2 (mixed mode) and a combination. At around 500 seconds, the events in opening mode has initiated and propagated to the entire depth showing smooth continuous rise in events and gradually decreasing there after. In the processes of yielding of steel, lot of events have formed in the midspan. Once sufficient events are formed at midspan, the load transfer mechanism and distribution gets transferred to other zones. At around 1500 seconds, the initiation and propagation of events in notch at quarter span occurs with smooth continuous rise of events in mixed mode to the loaded point resulting in shear cracking as seen in picture of Figure 15.

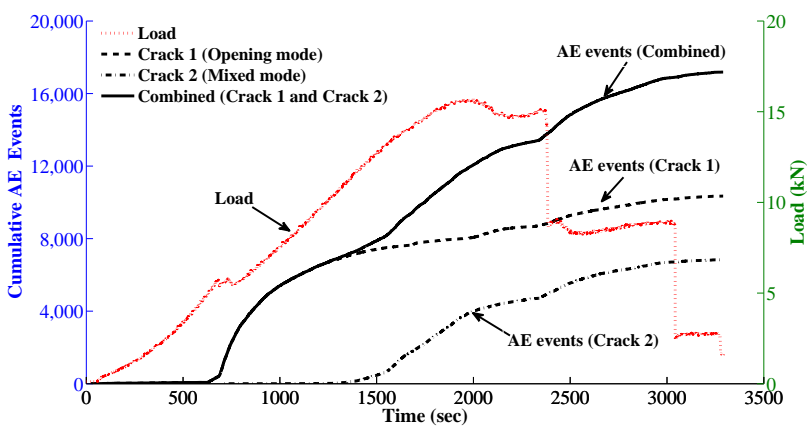

Figure 11: Plot of cumulative events and load with time 


\subsubsection{Absolute AE energy}

Absolute energy is defined as the integral of the squared voltage signal divided by the reference resistance (10 k-Ohm) over the duration of $\mathrm{AE}$ wave form. This is the true energy measure of AE hit. The unit of absolute energy is Atto joules $(\mathrm{aJ})$. The absolute energy $(\mathrm{aJ})$ recorded by each $\mathrm{AE}$ sensor depends on the spatial location of event. Nearer the event to the AE sensor, higher is the amount of absolute energy released to that sensor.

Figure 12 shows the cumulative absolute AE energy and load with time for the specimen. In this plots, the cumulative absolute energy with time is shown for crack 1 (opening mode), crack 2 (mixed mode) and combined for the zones of event shown in the picture of Figures 9 and 10 It is seen that there is a increase in the cumulative absolute AE energy until the complete testing of the specimen. The absolute energy contributed from opening mode in initial stage at around 500 seconds shows smooth continuous rise of events in midspan and there after becoming almost constant. When sufficient absolute AE energy is dissipated from midspan, the absolute AE energy is contributed from the mixed mode, which starts at 1500 seconds with sudden continuous rise of absolute energy. This sudden continuous rise of absolute AE energy for mixed mode is higher than smooth continuous rise of opening mode. This increase of absolute energy value is much higher in proportion to absolute energy value released by events in opening mode.

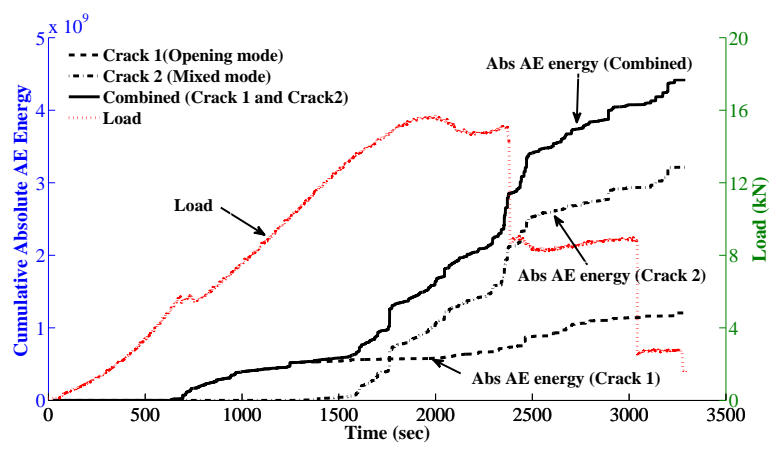

Figure 12: Plot of cumulative absolute AE energy and load with time

\subsection{3 $b$ - value and its application to $\mathrm{AE}$ data}

In seismology, earthquake events, can be quantified by magnitude-frequency relationship which was proposed in the empirical form by Gutenberg and Richter as

$$
\log _{10}(N)=a-b M_{L}
$$

For use in AE technique, the GutenbergRitcher formula from Equation 1 can be modified as [7] which is given below,

$$
\log (N)=a-b\left(A_{d B} / 20\right)
$$

where, $N$ is the incremental frequency (i.e. the number of $\mathrm{AE}$ hits with amplitude greater than the threshold $A_{T}$ ), $a$ is an empirical constant and $b$ is the $b$-value. The $b$-value is the negative gradient of the log-linear AE frequencymagnitude plot and hence it represents the slope of the amplitude distribution. The $b$-value changes systematically with different stages of fracture growth, so it could be used to estimate the development of fracture process [6].

The AE events data from picture are divided into crack 1 (opening mode) and crack 2 (mixed mode) as shown in the Figures 9 and 10 . The analysis was carried out on a group of 200 events from the AE data. The amplitude distribution was from the threshold set value of 40 $\mathrm{dB}$ to $100 \mathrm{~dB}$. This distribution was grouped in steps of $15 \mathrm{~dB}$ ranging from 40 to $55 \mathrm{~dB}, 55$ to $70 \mathrm{~dB}, 70$ to $85 \mathrm{~dB}$ and 85 to $100 \mathrm{~dB}$. In each of the amplitude ranges, the number of $\mathrm{AE}$ events are counted. The graph of log number of events versus magnitude of amplitude divided by 20 is plotted for each group. For the above data points, the linear trend is fit using least square method. The slopes of such graphs represent the $b$-value. The time of the $b$-value is end time in seconds of the last event of that particular group. The $b$-value were plotted against time. The filtered AE data is analysed using a program written in MATLAB in order to carry out the $b$-value analysis.

Figure 13 and 14 shows the plot of variations of $b$-value and load with time for the beam spec- 
imen in opening mode and mixed mode. The micro-cracks generate large number of small amplitude acoustic emission events and hence $b$-value is relatively high during initial stages. The macro cracks generate less number of high amplitude acoustic emission events and hence $b$-value is relatively low in later stages. With the increase in load level, fracture process moves from micro to macro cracking and $b$-value decreases. This helps in understanding, at what level of load and time, the micro-cracking initiation, coalescence of micro-cracks and macrocrack propagation is taking place in opening mode and mixed mode.

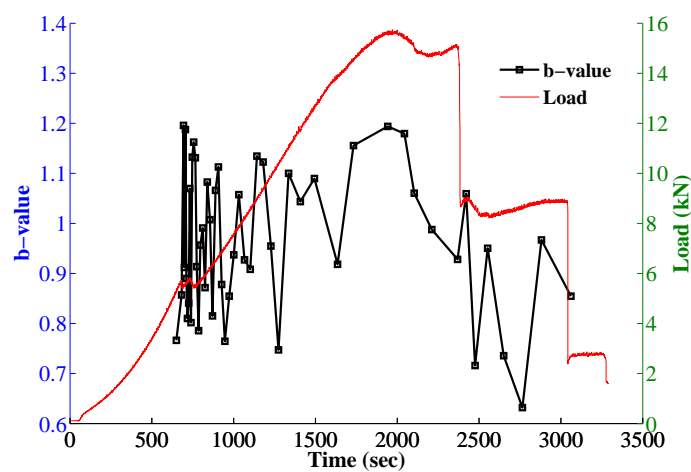

Figure 13: Variation of $b$-value and load with time for crack in opening mode

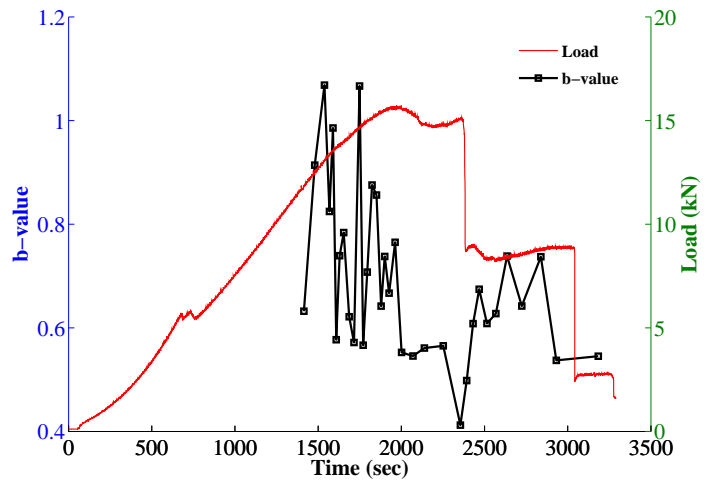

Figure 14: Variation of $b$-value and load with time for crack in mixed mode

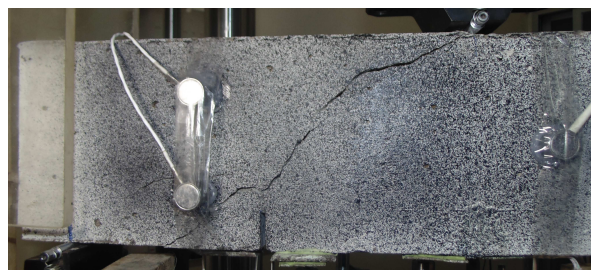

Figure 15: Figure showing the failure pattern of beam specimen in front view

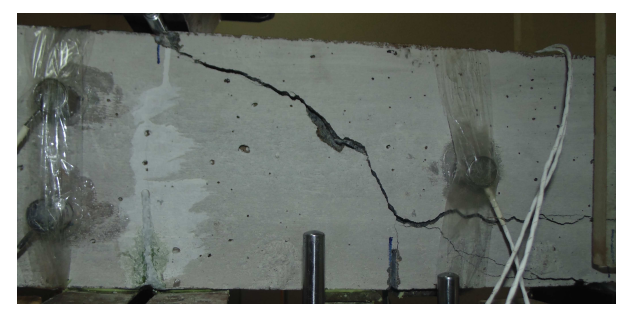

Figure 16: Figure showing the failure pattern of beam specimen in back view

\section{CONCLUSIONS}

In this study, the Acoustic Emission (AE) technique has been used for monitoring the mixed mode crack growth in reinforced concrete. The specimen was reinforced with single longitudinal bar with diameter of $8 \mathrm{~mm}$ (percentage $=0.66 \%$ ) with no stirrups. The notch is provided at the quarter span, as it is the region prone for mixed mode crack initiation and propagation. The specimen is tested in three point bending under displacement/stroke control in the closed loop servo controlled hydraulic testing machine. The data from load, CMOD, displacement and strain in steel were useful to understand the behaviour of reinforced concrete in opening and mixed mode.

Location for AE events for specimen corresponding to different points of load is studied. The spread of the events and its distribution causing cracking and fracture processes is discussed. This helps in sequence of mechanisms taking place in reinforced concrete. AE data are divided into opening mode and mixed mode based on the events occurring in the zones. This is further compared in terms of growth and rise of events and absolute energy released with time. b-value indicates the fracture growth processes at different stages in opening and mixed 
mode. The acoustic emission is very important tool to predict the crack growth in opening mode and mixed mode which helps in the better understanding of reinforced concrete and different mechanisms taking place.

\section{REFERENCES}

[1] Jacinto R Carmona, Gonzalo Ruiz, and Javier R del Viso. Mixed-mode crack propagation through reinforced concrete. Engineering Fracture Mechanics, 74(17):27882809, 2007.

[2] Alberto Carpinteri, Jacinto Ruiz Carmona, and Giulio Ventura. Failure mode transitions in reinforced concrete beams-part 2: experimental tests. ACI Structural Journal, 108(3):286-293, 2011.

[3] Shohei Momoki, Hwakian Chai, Dimitrios G Aggelis, Akinobu Hirama, and Tomoki Shiotani. Acoustic emission for characterizing behavior of composite concrete elements under flexure. $J$ Acoust Emission, 27:186-93, 2009.

[4] Dimitrios G Aggelis, Dimitra Soulioti, Nektaria M Barkoula, Alkiviadis S Paipetis,
Theodore E Matikas, and Tomoki Shiotani. Acoustic emission monitoring of steel-fiber reinforced concrete beams under bending. Prog AE, 14:287-94, 2008.

[5] Manindra R Kaphle, Andy CC Tan, David P Thambiratnam, and Tommy HT Chan. Study of acoustic emission data analysis tools for structural health monitoring applications. In Progress in Acoustic Emission XV: Proceedings of the 20th International Acoustic Emission Symposium. Japanese Society for Non-Destructive Inspection, 2010.

[6] Ing S Colombo, IG Main, and MC Forde. Assessing damage of reinforced concrete beam using b-value analysis of acoustic emission signals. Journal of materials in civil engineering, 15(3):280-286, 2003.

[7] MVMS Rao and KJ Prasanna Lakshmi. Analysis of b-value and improved b-value of acoustic emissions accompanying rock fracture. Current Science, pages 1577$1582,2005$. 